\title{
A PAISAGEM BARROCA COMO MEMÓRIA ESTÉTICA NACIONAL
}

Everaldo Batista da Costa ${ }^{1}$

\begin{abstract}
RESUMO - A paisagem barroca, considerada elemento de uma memória estética nacional, guarda o espírito da empresa que produziu o território colonial: a rigidez de um sistema vertical de controle absoluto da produção artístico-religiosa e do urbanismo que passam a caracterizar as cidades, no litoral e no interior do Brasil. Nesse aspecto, este artigo sugere, metodologicamente, o estudo da arte e do urbanismo barrocos brasileiros através da correlação entre memoria estética e território forjado, em consonância com a vida material e espiritual da sociedade moderna Européia.
\end{abstract}

Palavras-chave: Cidades coloniais do Brasil; paisagem barroca; memória estética.

ABSTRACT - The BAROQUe LANDSCAPE AS NATIONAL AESTHETIC MEMORY. The Baroque landscape, considered an element of a national aesthetic memory, preserves the spirit of the company that produced the colonial territory: the rigidity of a vertical system of absolute control of artistic-religious production and urbanism that characterize cities on the coast and in the interior of Brazil. This article suggests, methodologically, the study of Brazilian baroque art and urbanism through a correlation with aesthetic memory and forged territory, in line with the material and spiritual life of modern European society.

Keywords: Brazilian colonial cities; baroque landscape; aesthetical memory.

RÉSUMÉ - LE PAYSAGE BAROQUE EN TANT QUE MEMOIRE ESTHETIQUE NATIONALE. Ce paysage baroque garde l'esprit de l'entreprise qui a produit le territoire colonial brésilien: la rigidité du système vertical de contrôle absolu de la production artistique et religieuse, et de l'urbanisme - qui caractérise les villes brésiliennes tant sur la côte que dans l'intérieur. À ce sujet, notre article suggère, méthodologiquement, l'étude de l'art et de l'urbanisme baroques, en corrélant mémoire esthétique et territoire façonné, en conformité avec la vie matérielle et spirituelle de la société européenne moderne.

Mots clés: Villes coloniales brésiliennes; paysage baroque; mémoire esthétique.

1 Professor da Universidade de Brasília (UnB), Instituto de Ciências Humanas, Departamento de Geografia, cep- 70910-900, Brasília-DF, Brasil, Campus Darcy Ribeiro, Asa Norte. E-mail: everaldocosta@unb.br 


\section{PREÂMBULO: MEMÓRIA ESTÉTICA E PAISAGEM PRODUZIDA}

O princípio ou o pressuposto da reflexão apresentada é o de que a paisagem produzida é expressão da história territorial, ou seja, faz-se objetividade dos processos deslindados no território; é produto cultural e político que se transforma permanentemente, $o$ que redunda, variavelmente, em novas formas e novos conteúdos.

Paolo D’Angelo, em Os limites das actuais teorias da paisagem, diz que a Geografia tem pleno direito de falar da paisagem como a conformação física dos lugares, incluindo as transformações introduzidas pelos grupos humanos; o que se distingue da paisagem em sentido estético, pois aquela pode ser dada como um geossistema, esta não. Para D’Angelo (2011), a paisagem do geógrafo prefigura, especialmente, o domínio físico-natural; o autor traz uma carga de percepção geométrica e naturalista para a inquirição paisagística no campo do saber geográfico.

Outra via analítica é possível. O sentido estético da paisagem pode ser compreendido em consonância com a memória e a identidade sociais, por dizer respeito à experiência individual ou coletiva que se tem do espaço produzido historicamente. Natureza e cultura são analisadas, convergentemente, como dados e fundamentos da saga humana sobre territórios, de maneira que a memória estética da paisagem cria e recria vínculos afetivos, simbólicos, econômicos ou de experiências sobre uma base que é concreta e também imaginada. Cabe, assim, a reflexão de que as coisas visíveis sobre a superfície terrestre (objetos geográficos) resultam da natureza humana agida sobre a natureza terrestre; arruamentos com grandes armazéns, infraestruturas e automóveis não fazem de um pedaço de terra ainda uma paisagem; a consciência, como um todo unitário, produz a paisagem em um processo espiritual - segundo Simmel (2011) - ou seja, a paisagem (mesmo em recorte) é forma-conteúdo, produto da história territorial, resultado de ação política social.

Os valores criados na forja de territórios amalgamam-se à paisagem produzida, caso da arte enquanto expressão material e espiritual da história social. Não se parte, nesta abordagem, da paisagem em sentido físico imediato, mas dos elementos que, esteticamente, representam a política de territórios específicos e da memória social, processualmente. Nesse sentido, fala-se em uma identidade estética como a tomada do aspecto estético enquanto traço saliente da identidade local (D’Angelo, 2011), o que possibilita pensar o sentido de memória estética com respeito à retomada dos elementos que legitimam a memória social vinculada à configuração territorial. Logo, memória estética na e da paisagem corresponde à história do território e guarda o fazer e o refazer de significantes e de significados recordativos no espaço vivido, processualmente. Mais do que comportar elementos da cultura e da natureza, a paisagem guarda o espírito do território, que é resultado, por sua vez, de intencionalidades que remetem a buscas e a conquistas. Além de um valor estético cuja expressão direta é alcançada pelos olhos, a memória estética na e da paisagem diz respeito a modos de vida e a produções históricas, que dão o caráter concreto, subjetivo e ilusório de permanências em territórios de vivências múltiplas. A memória estética - que se faz em cultura material 
e imaterial sob base espacial -, em suma, diz respeito a recordações, vínculos sociais, trânsitos de coisas, significados e narrativas, que se preservam pela possibilidade da produção e da reprodução das paisagens que compõe o território. Paisagem pronuncia, sempre, culturas e vivências espacializadas.

Bosi (1986) fundamenta essa concepção de cultura aplicada à paisagem, à memória ligada à história de territórios. $\mathrm{O}$ autor critica o conceito de cultura enquanto alta soma de objetos da civilização, quando essa "é uma ideia que nos barbariza; no fundo somos bárbaros no sentido de que usamos os bens, mas não conseguimos pensá-los. No entanto, cultura é vida pensada". De acordo com Bosi (1986), em vez de tratar a cultura como soma de coisas desfrutáveis, coisas de consumo, devemos pensar a cultura como o fruto do trabalho. Memória e cultura (termo de raiz latina, que vem do verbo colo e significa cultivar a terra) subsidiam o entendimento da paisagem produzida, ao se fazer objeto estético, respectivamente, de recordações e do trabalho depositado nos lugares.

Tratar de uma memória estética da paisagem produzida justifica-se pelo tema e objetivo deste artigo, que entende a paisagem barroca como um elemento da memória estética nacional brasileira. Esta noção coaduna-se à recordação do controle e da complexização do território na escala do Brasil Colônia. A memória estética reproduz-se, particularmente, em diferentes aglomerados urbanos, por meio de elementos urbanísticos e artísticos representantes da religiosidade e do controle social, do ordenamento territorial e dos anseios da sociedade moderna europeia, tudo reproduzido, paisagisticamente, em terras coloniais. Dessa complexidade, advém o entrecruzamento de culturas, de uma memória e de uma arte que perfazem o patrimônio brasileiro (institucionalizado ou não), como antigos engenhos de açúcar, fazendas, sítios históricos e arqueológicos; complexidade que pode ser assimilada na correlação entre colonização e complexização do território.

A paisagem barroca, então, é materialidade triunfante de sentidos impressos ao território; perfaz expressão particular da transformação da natureza dentro de uma visão totalizadora da história movida pela economia mundial, cujo espírito enaltece-se na objetividade econômica que passa a ser subjetivada na arte. Nesse aspecto, a paisagem torna-se algo esteticamente presente no olhar de um contemplador sensível e sentimental, o qual pode ou não reconhecer campos diante da cidade, o rio enquanto fronteira, enquanto tais, como paisagem (Ritter, 2011).

Outra importante assertiva é a de que, para descrever a natureza em toda sua magnitude, não se deve ficar apenas em sua aparência exterior, pois é necessário representá-la na forma como se reflete no interior humano, preenchendo o nebuloso território dos mitos com graciosas formas e desenvolvendo as atividades artísticas da representação (Ritter, 2011). A poesia e as artes visuais, então, parecem se encarregar de compreender as dimensões da natureza graças à consciência humana sensível; fazem-se esteticamente presentes.

Assim, reconhece-se a arte (barroca) como expressão narrativa da vida material-espiritual, que aglutina experiência política, fazer econômico e sentidos culturais da complexização territorial e da produção de paisagens. A síntese justificativa para o trata- 
mento da arte e expressões do urbanismo barrocos como temas plausíveis da abordagem geográfica deve-se ao fato de assumirem funções universais no complexo particular de distintas paisagens urbanas históricas, as quais consubstanciam um rico patrimônio na América Latina e, em particular, no Brasil.

Memória estética e paisagem-arte produzida no Brasil colonial trazem, em germe, não apenas elementos de fruição ou contemplação contemporânea, mas congregam os sentidos paradoxais de liberdade e domínio na e da sociedade (ainda sobre a natureza) em seu vir-a-ser material e espiritual. O barroco é produzido e resplandece, esteticamente, para dar voz às angústias, aos interesses e à saga do homem moderno europeu, às verdades absolutas de um espírito empreendedor universal, o qual rebate em notáveis expressões territoriais e paisagísticas por toda América Latina.

Introdutoriamente, é necessário ressaltar um item na defesa da tese de uma paisagem barroca condutora histórica de uma memória estética nacional. A concepção de nacional (que adjetiva, ao longo deste estudo de cunho geográfico histórico: memória estética, Estado e identidade) decorre da constituição burguesa dos Estados nacionais modernos. Há um conflito encampado na construção de uma identidade territorial e ideológica de formação nacional (que envolve a busca de soberania e de autonomia), ao se supor a seleção aleatória de símbolos nacionais tratados por legítimos, em toda América Latina (Escolar, 1996). Para Marcelo Escolar, a seleção de objetos representativos de nacionalidade pode ser inclusiva e exclusiva, concomitantemente, e levar a rupturas com outras identidades, dada a priorização ou a criação de novas identidades. Assume-se o barroco, então, como um dos elementos simbólicos das nacionalidades latino-americanas: dos sujeitos históricos (incorporados ou não em suas representações) ao Estado (enquanto superestrutura social absoluta).

O pré-requisito necessário para a conformação material de qualquer Estado-nação moderno corresponde à apropriação exclusiva de um território, para se fazer, a posteriori, o processo de integração social ligado à hegemonia do capital e da burguesia como classe dominante; esse marco referencial geográfico, cuja delimitação obedece a um sem número de causas alternativas é parte imprescindível da formação nacional (Escolar, 1996).

Em síntese, a ideia de nacional aqui assumida tem como fundamento a base material de domínio estatal do território. Envolve poder e controle sociais (que demandam representação objetivo-subjetiva de identidade histórica); os quais têm, por sua vez, suporte na ampla zona dos barrocos mineiro e litorâneo, enquanto símbolos de nacionalidade, sobretudo para o Brasil do primeiro e do segundo quartel do século XX.

\section{NOTAS SOBRE O BARROCO E SUAS EXPRESSÕES ESPACIAIS: ARTE E URBANISMO}

Parece ser recorrente na análise teórica do barroco o problema da redução deste fenômeno a um só denominador: a expressão artística. Porém, junto a essa expressão que ganha tônus distintos em variados países do mundo, outro denominador comum do bar- 
roco diz respeito à sua emergência na era moderna, com caráter civilizatório. O conceito barroco foi aplicado no século XVIII, quando aparece pela primeira vez, conforme a teoria da arte de então, tratando-o como desmedido, confuso e extravagante. "Todos rechazan el Barroco a causa de su 'falta de reglas', de su 'capricho"' (Hauser, 1969, p. 99).

Hauser (1969) afirma que essa arte surge como antítese dialética da arte do século XVI, e não como sua continuação, de certa forma subestimando a significação do subjetivismo no Renascimento e a sobrestimação no barroco. Para o autor, não se pode falar nunca de um estilo unitário, que domine todos os tempos e lugares, pois em cada momento há tantos estilos diferentes quanto são os grupos sociais que produziram essa arte, especialmente "el barroco de las cortes católicas", como denomina. Com o barroco, a arte sagrada se diferencia da profana, definitivamente. No Renascimento e na Idade Média, havia infinitas formas de transição entre as obras de arte que serviam para fins puramente eclesiásticos e as que serviam para fins profanos; mas no decorrer da evolução da arte barroca realiza-se a fundamental divisão (Hauser, 1969).

O barroco ganha duas dimensões de análise: como degeneração da Renascença, por um lado, e, por outro, mais como uma noção geral de civilização do que como um estilo - o barroco é enaltecido como categoria da civilização europeia do século XVIIi. Nesse contexto, o barroco privilegia a visão como sentido abstrato ou intelectual. Arte-paisagem demasiado comprometida com a historicidade, a persuasão, o controle e a atração dos indivíduos para o seio da Igreja (e do controle do Estado), o barroco vincula-se, originária e ordinariamente, ao Concílio de Trento $\mathrm{o}^{\mathrm{ii}}$ e ganhou funcionalidade estratégica na América Latina, ao ostentar a dimensão faustica do poder eclesiástico e estatal; a paisagem produzida favorecia o controle do território de uma sociedade que se constituía a ferro e fogo, em nome do mercantilismo e do bulionismo.

Neves (1986) lembra que alguns teóricos tentam demonstrar o Concílio como fonte maior e viva da arte e do pensamento da época que vai rebater sobre as cidades. Atribuem a decretos do Concílio a fonte inspiradora dos artistas, indo mais longe ainda: reconhecem ligações entre a arte religiosa e a dimensão simbólica e alegórica próprias da arte profana da época. Para o autor, tornam-se os clérigos inspiradores de toda a arte nascente no barroco; identifica-se um determinismo entre fórmulas de Trento e inspiração artística; mesclam-se princípios da devoção com a arte, trata-se de misticismo, heroísmo, santidade, triunfo, êxtase, propaganda, martírio, erotismo, controle, formalismo, culto das imagens e culto à imagem.

Porém, nesse contexto político-religioso europeu, epicentro espaço-temporal das cidades coloniais barrocas brasileiras, deve-se reconhecer que a sensibilidade da arte não seria consequência do Concílio, de pensamentos ou sentimentos dele advindos - para concordar com Neves (1986) - mas, ao contrário, representa uma das muitas fontes de onde brotou a possibilidade de Trento, como do absolutismo. "O que equivale a compreendermos não terem sido os clérigos, principalmente os jesuítas, norteadores da sensibilidade e da imaginação do povo, mas, antes, influenciados pelas exigências da devoção popular e do médium artístico próprio da época" (Neves, 1986, p. 122). Em última análise, o barroco identifica-se com o poder estatal, onde o "exibicionismo absolutista leva- 
ria, fatalmente, às formas barrocas, únicas capazes de corresponder às solicitações da ambição ilimitada de domínio (...) o absolutismo é um conceito cuja conotação mínima exige ao menos dois termos: poder e ilimitação" (Machado, 1973, p. 91). Por assim considerar, o absolutismo moderno estabeleceu um esplendor por meio do déspota que se traduz na própria arte e, no caso latino-americano, serviu ao controle ou ao governo de uma massa social que se hibridizava, em ebulição.

Enquanto arte de uma nova burguesia, pode-se dizer que o barroco no Brasil e na América Latina, edificado pela Igreja e pela população colonial nascente - em consonância com o Estado - Ordens Religiosas e leigos (mineiros, fazendeiros, comerciantes), através das grandes obras, cumpriu a missão de aumentar o prestígio social e espiritual desta nova classe. Geograficamente, o barroco faz-se plural, pela América Latina. Lembra-nos Bayón (1982) que, nesta região, encontramos ao menos nove barrocos: o mexicano (fig. 1), o caribenho, o centro americano, o setentrional sul-americano (fig. 2), o da costa peruana e chilena, o do altiplano, o da planície e da floresta argentino-paraguaia, e, enfim, o do Brasil, em duas macrorregiões: a do Nordeste (e suas prolongações) e a do Rio de Janeiro e Minas Gerais (também com suas extensões).

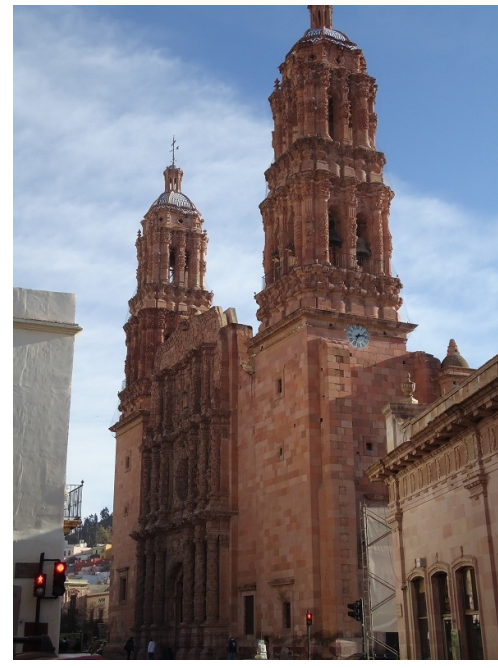

Fig. 1 - Catedral Basílica de Zacatecas, México (Janeiro 2012).

Figura a cores disponível online.

Fig. 1 - Cathedral Basilica of Zacatecas, Mexico (January 2012).

Colour figure available online.

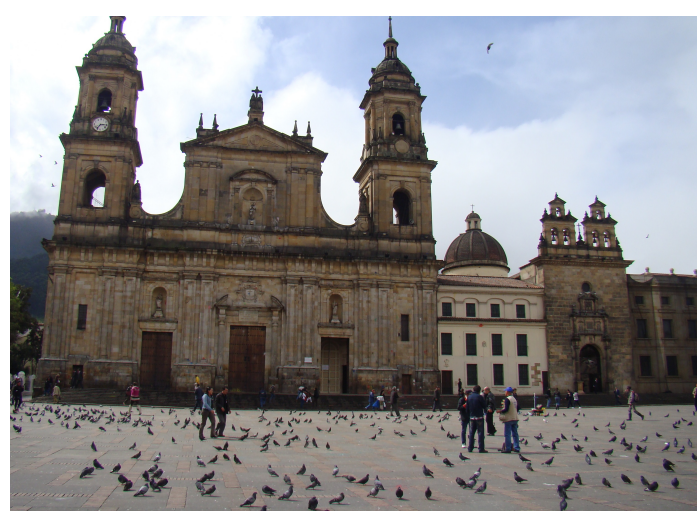

Fig. 2 - Plaza de Armas e Catedral de Bogotá, Colômbia. (Maio 2013).

Figura a cores disponível online.

Fig. 2 - Plaza de Armas and the Cathedral of Bogota, Colombia (May 2013). Colour figure available online.

Feita essa introdução sobre o espírito do barroco europeu, ressalta-se, também, o interesse em mencionar algumas expressões concretas da arte e do urbanismo barrocos sobre o território. Este tópico aborda essas expressões de forma global para, posteriormente, se considerar as representações deste fenômeno especificamente no Brasil. 
Antes que o barroco tomasse conta de todos os aspectos da cena, a renascença foi uma fase intermédia na qual o novo e o antigo se mesclaram. No que diz respeito às cidades, os elementos deste novo momento são descritos por Mumford (1991, p. 379):

\begin{abstract}
"Os símbolos desse novo movimento são a rua reta, a ininterrupta linha horizontal de tetos, o arco redondo e a repetição de elementos uniformes, cornijas, lintéis, janelas e colunas, na fachada. Alberti sugeriu que as ruas tornar-se-ão muito mais nobres se as portas forem construídas todas segundo o mesmo modelo, e as casas de cada lado ficarem em linha uniforme, não sendo qualquer delas mais alta que as outras. Essa clareza e simplicidade foram engrandecidas pela fachada bidimensional e pela abordagem frontal; mas a nova ordem, enquanto ainda vivia, jamais foi obedecida com qualquer coerência absoluta, como a que foi introduzida pelo século XVII, com suas rigorosas regras de composição, suas intermináveis avenidas e suas regulamentações legais uniformes."
\end{abstract}

As modificações formais artístico-urbanas, da renascença ao barroco, não podem ser interpretadas como mudanças de gosto ou de visão estética apenas; a influência exercida no planejamento de cidades adveio, em todos os pontos, das amplas transformações políticas e econômicas modernas. Para compreender o plano barroco que tomou forma, finalmente, pelo fim do século XVII, criando novos bairros e até mesmo novas cidades residenciais para a realeza, deve-se acompanhar as transferências de autoridade e poder que tiveram lugar no fim da Idade Média, diz Mumford (1991). Cidade barroca é um termo que guarda uma descrição política e social do período moderno e não mera referencia arquitetônico-estética.

O conceito barroco traz em si dois elementos contraditórios, desde seu surgimento, na Europa, os quais se complementam e se destacam nos territórios ordenados e controlados, bem como na paisagem produzida. Em primeiro lugar, seu aspecto matemático e abstrato, expresso com perfeição no rigoroso plano de ruas, nos traçados urbanos formais e nos desenhos geométricos de jardins, paisagens e espaços abertos; ao mesmo tempo, se destaca na pintura e na escultura do período, abrange o lado sensual, rebelde, extravagante, anticlássico, antimecânico revelado nas roupas e na vida sexual, bem como no fanatismo religioso e no desvairado estadismo (Mumford, 1991).

Pode-se dizer que o desenvolvimento do fenômeno barroco é acompanhado pela nova perspectiva que se cria do espaço. Mumford (1991) entende que um dos grandes triunfos da mentalidade barroca foi organizar o espaço, tornando-o contínuo, reduzindo-o à medida e à ordem, estendendo os limites da grandeza, para abranger o extremamente remoto e o extremamente pequeno; finalmente, associando o espaço ao movimento e ao tempo surge, nas características típicas do planejamento barroco, a perspectiva longa e a vista para dentro do espaço, descoberta por pintores (espaço entendido por Mumford na perspectiva arquitetônica e não geográfica). Ao passo que o espaço barroco convidava ao movimento, à viagem, à conquista pela velocidade, o tempo barroco não tinha dimensões, era um contínuo, de momento para momento; exprimia-se não como algo cumulativo, mas como uma quantidade de segundos e minutos (Mumford, 1991). 
Lei, ordem, uniformidade são produtos especiais da capital barroca (a Europa); mas a lei existe para confirmar situações e assegurar posições das classes privilegiadas; a ordem é uma ordem mecânica, baseada não no sangue, na vizinhança ou nas finalidades de parentesco e nas afeições, mas na sujeição ao príncipe reinante; e quanto à uniformidade - é a uniformidade do burocrata, com seus escaninhos, seus processos, sua papelada, seus numerosos métodos de regularizar e sistematizar a coleta de impostos, coloca-nos Mumford (1991, p. 399) e prossegue:

\begin{abstract}
"Assim, os governantes barrocos voltaram a enunciar todas as instituições da implosão urbana original, e mesmo, em certos casos, a união dos poderes sagrado e temporal numa Igreja do Estado, presidida por um rei de designação divina. $\mathrm{O}$ antigo Deus da cidade tornava-se agora uma divindade nacional, assim como as antigas muralhas da cidade passavam a ser as 'fronteiras nacionais."
\end{abstract}

A nova ordem urbana barroca era, definitiva e exuberantemente, artística e política. Caracterizada pela praça aberta ou cercada, com suas avenidas e ruas irradiantes, atravessando imparcialmente antigos emaranhados ou novas redes, movendo-se para o horizonte sem limite ou com fundo em perspectiva a destacar edifícios (fig. 3). Com relativa ausência do espaço interior, a planta em asterisco era, em verdade, uma contribuição barroca; o urbanista barroco transformou aquele conceito esquecido em fato solene; tinha, porém, suas razões profissionais, de tal ponto central, a artilharia podia dominar todas as estradas; o protótipo ideal do plano barroco era baseado em considerações militares que remontam a traçados octogonais, com ruas que se irradiam do centro (Mumford, 1991).

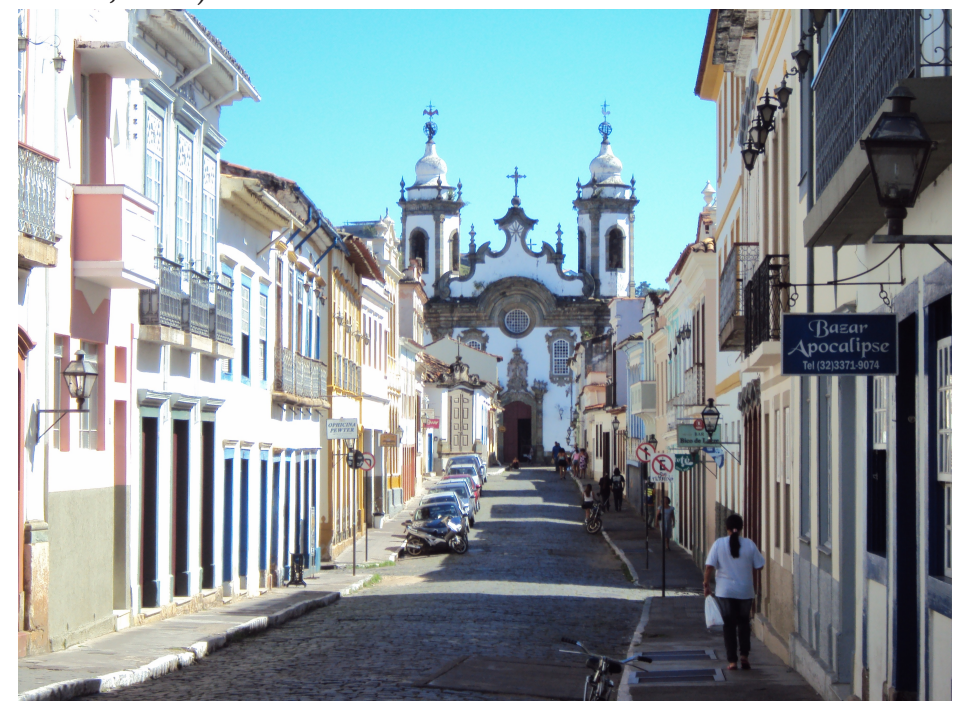

Fig. 3 - Rua Direita, em São João del-Rei, Minas Gerais, Brasil (Março 2014).

Figura a cores disponível online.

Fig. 3 - Broad Street, in São João del-Rei - Minas Gerais, Brazil (March 2014).

Colour figure available online. 
Para Mumford (1991), as dimensões das construções foram alteradas na cidade barroca, com a valorização do sítio central, dos círculos ou praças abertas dominadas por monumentos, flanqueadas simetricamente por edifícios públicos, além da disposição de avenidas a partir de tais centros; ao contrário da cidade medieval, através da qual se deve caminhar lentamente, para apreciar suas incessantes transformações de massa e silhueta, seus detalhes complicados e surpreendentes, pode-se perceber toda uma cidade barroca quase de um só olhar; mesmo aquilo que não se vê pode-se facilmente introduzir na imaginação, uma vez que se achem estabelecidas as linhas de orientação; a avenida representa a moldura horizontal dos edifícios terminais; o efeito principal do planejamento barroco era aumentar a importância das linhas horizontais reguladoras, formadas por lintéis, molduras e cornijas, tudo unido pela extensão aparentemente infinita da avenida.

"A planta barroca era uma realização baseada em quarteirões. Tinha de ser traçada de um só golpe, fixa e congelada para sempre, como se feita da noite para o dia por gênios das Mil e Uma Noites. Tal planta exige um déspota arquitetônico, a trabalhar para um governante absoluto, que viverá o tempo suficiente para completar suas próprias concepções. Alterar esse tipo de planta, introduzir novos elementos de outro estilo, é romper sua espinha dorsal estética. O próprio conteúdo superficial de uma planta barroca só pode ser preservado por severos regulamentos administrativos. Onde tais regulamentos foram conservados, como em Paris, a ordem pôde ser preservada na superfície, por muitas gerações, mesmo por séculos." (Mumford, 1991, p. 426).

O mundo barroco fez-se racionalizado e geométrico, em contraposição a falta de geometria da cidade gótica. O barroco, em sua dimensão urbanística, deve ser visto como fenômeno da criação de um novo tipo de cidade que é testemunho da diferenciação social e de um mundo em ebulição e emergente transformação. A cidade barroca fez-se cenário ou campo aberto, onde a paisagem traduz vocação para o espetáculo e origina a importante criação do barroco: a fachada. Como destaca Romero (2009, p. 167):

"Se trata, entonces, de una nueva, escindida, que adopta un tono de vida barroco, caracterizado por su tendencia a la espectacularidad, y que se aloja en una ciudad que, a vez, se escinde y se presta a esta tendencia. En la ciudad barroca, como antes en la ciudad gótica, germina e irrumpe, al cabo de muy poco tiempo, una nueva corriente de ideas, una nueva mentalidad y un ejercicio y un análisis de una forma de vida inédita.”

Fica por conta do jardim - em uma composição métrica do espaço - ou parque do século XVII, o símbolo mais representativo do planejamento barroco, em seus momentos mais criadores ou mais débeis (Mumford, 1991). A literatura analisada aponta que, no plano barroco, nenhuma ação foi promovida pelos núcleos cívicos; o mercado e a escola não ganharam sítios especiais; o parque dentro das grandes praças não servem, sequer, como locais de lazer para as crianças; as instituições da municipalidade encontram-se subordinadas ao palácio real; o palácio, o fisco, a prisão e o hospício resumiam a ordem inédita que regia a nova vida política barroca.

Com esse escopo urbano e artístico, fizeram-se, nas Américas, um mundo de novas cidades que conservaram o poder, a religião e os costumes, agora híbridos, dos coloniza- 
dores (além de representações da autoridade metropolitana); o barroco serviu como élan destas permanências expressas nas paisagens produzidas no Novo Mundo. O historiador das cidades José Luiz Romero sintetiza essas ideias ao considerar que:

"Imitación de las europeas, las ciudades coloniales no solo repitieron su aspecto físico,
com el trasplante de su arquitectura, sino que repitieron también su las formas de vida:
México o Lima quisieron ser cortes como las españolas; Bahia o Río de Janeiro, como
las portuguesas. Y cada europeo trasplantado trato de reconstruir su ambiente originá-
rio en la iglesia suntuosa que se erigia, en el mobiliário con que adornaba su morada y
en los modales que adoptaba para no ceder a la tentación de lo que consideraba la
barbárie circundante." (Romero, 2009, p. 228).

As sintéticas anotações sobre o barroco aqui postas - em escala mais geral - servem de baliza para tratar do barroco brasileiro como elemento da memória estética nacional. Tanto na Europa como na América colonizada, a profusão desta arte e urbanismo fez-se com palácios e igrejas (enquanto simbólicos burgueses das cidades barrocas), com uma concepção de espaço que, em certa medida, corresponde à de sociedade, dentro de três concepções: do fausto, da ostentação e da contradição.

\section{A PAISAGEM BARROCA COMO MEMÓRIA ESTÉTICA NACIONAL: CASO BRASILEIRO}

Já se afirmou que o sentido estético da paisagem revela-se com a memória e com a identidade sociais, por dizer respeito à experiência individual ou coletiva que se tem do território configurado historicamente. A memória estética da paisagem cria e recria símbolos por meio de narrativas produtoras de significantes e de significados, ante o espaço vivido. No Brasil, o barroco e a paisagem barroca - a arte religiosa e traços do urbanismo barroco, respectivamente - fazem-se elementos cruciais de uma memória estética nacional. Arte esta que traz o conteúdo de trânsitos políticos e de fazeres econômicos pelo território brasileiro e mais, por ação e escolha do governo Getúlio Vargas (1930-1945), passou a representar o Estado-nacional em afirmação oiii. Cumpre lembrar, com Escolar (1996), que no percurso de uma delimitação territorial e imaginária da nação, o Estado atrela desenvolvimento à necessidade de coerção cultural e econômica, em prol da denominada nacionalidade.

A compreensão da paisagem barroca brasileira (produzida na sociedade dos séculos XVII e XVIII, especialmente) por meio da categoria de memória estética nacional (entendida a partir da retomada estratégica do barroco, nos anos 1930) relaciona-se com diferentes contextos ou políticas promotoras da apropriação dessas paisagens (o que não é o foco central deste trabalho, o qual é dedicado à dimensão histórica e espacial do barroco brasileiro). Porém, para o melhor esclarecimento da origem da ideia de uma memória estética nacional centralizada na paisagem barroca, esclarece-se a periodização (realizada em outra pesquisa) que sugere cinco indissociáveis eventos ${ }^{\text {iv }}$ dos mais marcantes da geografia histórica das cidades coloniais da antiga zona mineradora. 
Periodização que denota um movimento resultante da formação socioespacial brasileira, de modo que o barroco é a expressão ressignificada em cada uma das cinco fases. A atual dinâmica urbano-territorial dessas cidades deve ser compreendida através desses momentos, que são dos mais significativos da formação dos antigos núcleos da mineração brasileira, uma vez que a valorização econômica vigente está calcada na alegação do valor simbólico que representam e no capital simbólico que agregam, ao longo de sua história. Esses cinco momentos ou fases significativas da periodização proposta são, conforme Costa (2011, p. 45):

1. As cidades coloniais como particularidade de um devenir universal - o barroco emerge enquanto evento global que ganha uma feição particular, nos núcleos da mineração no Brasil do século XVIII, envolvidos pela dinâmica da economia mundial e da economia-mundo (Braudel, 1985) que favorecem o se quer denominar Gênese do patrimônio no Brasil.

2. As cidades coloniais como territórios de identidade, quando o barroco é reconhecido como símbolo cultural do novo Estado-nação, na década de 1930, com o Governo de Getúlio Vargas e a criação do SPHANv; o que se trata por fase da Produção simbólica do patrimônio no Brasil.

3. As cidades coloniais como territórios de identidade do capital, com a incipiente projeção mercantil do barroco, nos anos de 1960, fase do empreendedorismo urbano (Harvey, 2005) e da concomitante elaboração de cartas internacionais que apontam para a possibilidade de mercantilização dos centros históricos, internacionalmente, o que leva à denominada Projeção inicial do patrimônio no Brasil.

4. As cidades coloniais como cidades-patrimônio-mercadoria na fase da banalização pela cenarização progressiva do patrimônio que conduz à reinvenção do barroco e à recolonização dos centros históricos, após a década de 1990, induzindo a uma nova dinâmica territorial nas cidades coloniais, que urgem serem entendidas como totalidades urbanas inseridas na totalidade-mundo - tese central dessa periodização que aponta o barroco como elemento de ressignificação do próprio território dessas cidades brasileiras.

5. As cidades coloniais barrocas - como possibilidade de vir a ser - de empoderamento dos bens materiais e simbólicos por parte das populações locais.

A apresentação desta periodização tem cunho explicativo, quando se deve considerar, de fato, que uma memória estética nacional não se faz por si ou que a paisagem barroca não se faz memória a priori ou sem intencionalidade social; no Brasil e pelo barroco, ela se dá no contexto de uma dialética dos cinco momentos pensados. Se há diferentes apropriações dessa paisagem, ao longo da história (analisadas pelas fases sugeridas por Costa, 2011), o que se pretende aqui é categorizar memória estética nacional, a partir da ideia de uma paisagem barroca em devir.

Logo, serão retomadas as dimensões formais e de conteúdo que projetaram e projetam, ontem e hoje, o barroco brasileiro: uma contribuição geográfica possível à análise de 
uma paisagem barroca. É corrente, na literatura científica brasileira, a análise sobre a cidade colonial de origem Portuguesa em contraste com as cidades coloniais da América Espanhola - tratadas como primor ou rigor uniforme do planejamento - de maneira que as primeiras trouxeram traçado irregular em resposta a uma topografia que, em certa medida, já as faziam barrocas na gênese, não correspondente com a racionalidade perpendicular do tabuleiro de xadrez hispano-americano. Ao contrário, por longo período, as cidades coloniais brasileiras foram consideradas "anárquicas", "medievais", "espontâneas", "produtos do desleixo", "semeadas ao acaso". Dentre os autores que as abordaram desta maneira, destacam-se Sérgio Buarque de Holanda, Robert Smith, Aroldo de Azevedo e outros...

"A cidade que os portugueses construíram na América não é produto mental, não chega a contradizer o quadro da natureza, e sua silhueta se enlaça na linha da paisagem. Nenhum rigor, nenhum método, nenhuma providência, sempre esse significativo abandono que exprime a palavra 'desleixo"' (Holanda, 1995, p. 110).

“Tal era o padrão de construção urbana que os colonizadores portugueses trouxeram para o Novo Mundo, depois de o terem levado à Madeira, aos Açores, à África, à Índia e à China. As primeiras povoações costeiras do Brasil - Bahia, Olinda e o Rio de Janeiro - cresceram de maneira tão irregular e pitoresca quanto Funchal e Porta Delgada, Luanda, Goa ou Macau." (Smith, 1969, s. n. t.).

Este estudo, entretanto, é contraponto às abordagens do acaso ou do desleixo na produção dessas cidades, assim como também o são os estudos de Nestor Goulart Reis Filho, Giovanna Brenna, Mauricio de Almeida Abreu, dentre outros. A paisagem barroca identificada como elemento de uma memória estética nacional traz uma ordem que expressa o espírito da empresa que produzia o território colonial: a rigidez de um sistema vertical pelo controle que se dava por meio da produção artístico-religiosa, do urbanismo que passam a caracterizar as cidades, bem como do aparato burocrático institucional português, tanto no litoral quanto no interior do Brasil.

Sobre a organização da cidade colonial portuguesa, na América, cuja arte barroca faz-se elemento sintético e objeto do que se denomina aqui memória estética nacional, Giovanna Brenna deixa relevantes apontamentos:

"É o caso das cidades diretamente dependentes do governo central, planejadas por arquitetos e engenheiros militares, como Salvador da Bahia - cujo núcleo fortificado, devido a Luis Dias, apresentava um traçado relativamente regular -, São Luis do Maranhão, com plano em xadrez do engenheiro-mor Francisco Frias de Mesquita, e Belém do Pará. O Rio de Janeiro, fundado em 1565 no topo do Morro do Castelo, adota uma estrutura tendente ao xadrez na fase sucessiva de sua expansão na área plana entre os quatro morros que delimitam naturalmente o seu perímetro (séculos XVII e XVIII); e são bem reconhecidas, no século XVIII, as preocupações da Câmara de Salvador para garantir o alinhamento das moradias e a racionalização da estrutura urbana, que tinha se desenvolvido de maneira espontânea depois do planejamento inicial." (Brenna, 1982, p. 142). 
Em estudo anterior, foram indicados alguns elementos caracterizadores dessas cidades coloniais, que as tornam símbolos paisagístico-memoriais do Brasil histórico. Nessa análise, é indicada a correlação entre os espaços simbólicos do Estado Absolutista junto aos espaços simbólicos da nova burguesia que se formava, especialmente, nos núcleos urbanos da ampla zona da mineração brasileira (de Minas Gerais a Goiás e Mato Grosso); tal correlação perfazia uma ordem espacial que nega o discurso do desleixo na produção de tais cidades.

“(...) identificamos, em algumas análises, notória generalização sobre a cidade colonial do Brasil, ligando-as, sobretudo, ao 'desleixo' ou à impropriedade 'mental'. Algumas dessas análises não delimitam o período nem a área estudada; muitas vezes, não fazem referência a fontes primárias ou arquivos ultramarinos, limitando-se a referenciar o vasto período colonial, que perdurou mais de três séculos (...) Pelo fato das manifestações artísticas e arquitetônicas barrocas terem se apresentado num contexto histórico e espacial diferente do europeu, em Minas Gerais, acabou adquirindo configuração diversa (...) Nesse sentido, para entendermos essa diferenciação, podemos analisar a ordenação dos núcleos urbanos das Geraes sob duas perspectivas de produção do espaço que, no nosso entender, se interagem e se complementam, tornando-se indissociáveis ao ocorrerem em um mesmo plano: sob a ótica dos espaços simbólicos do Estado absolutista (construções religiosas) e sob a ótica dos espaços simbólicos de uma nova burguesia comercial (construções civis), onde os primeiros impuseram, sob o símbolo do barroco, o ordenamento e o ritmo aos segundos, constituindo o urbanismo barroco das Geraes." (Costa, 2009, p. 122).

Os agentes indissociáveis que dão corpo à paisagem favorecedora de uma memória estética brasileira são o Estado e a Igreja [mantidos por uma população nova], protagonistas do ordenamento sociourbano colonial, sobretudo nos primeiros três séculos de colonização; formaram espaços simbólicos do absolutismo português, sabedores da importância social estratégica dos signos de fausto e de opulência, por meio da arte religiosa. Nessas paisagens produzidas, a estética de ostentação fez-se arma de persuasão das populações para o seio do catolicismo, bem como favoreceu o controle social e do ordenamento dos núcleos coloniais. A Igreja se serve do barroco como um meio poderoso de persuadir, de conquistar os corações à fé pela admiração de uma estética ofuscante; o desleixo não potencializaria o controle socioespacial, muito pelo contrário. A espacialidade barroca reflete o cuidado urbanizador português; junto à Igreja, faz-se símbolo máximo do poder coercitivo da Coroa, na antiga zona da mineração brasileira; caso singular dessa espacialidade é a que congrega duas igrejas das Ordens Terceiras (N. Sra. do Carmo e São Francisco de Assis), o pelourinho e a antiga Casa de Câmara e Cadeia, reunidos na Praça Minas Gerais, na cidade de Mariana (fig. 4). Estado, Igreja e arte fazem-se presentes, pelo controle da sociedade mineradora, em matéria e espírito que remete à memória estética nacional. Ainda, constata-se o zelo urbanizador português pelo traçado de algumas dessas cidades, como Tiradentes, cujo sítio original emoldura-se quase que em um quadrado, tendo como importante eixo a retilínea Rua Direita (fig. 5), cujo sentido atual se faz por uma paisagem e uma arte de consumo turístico intenso. 


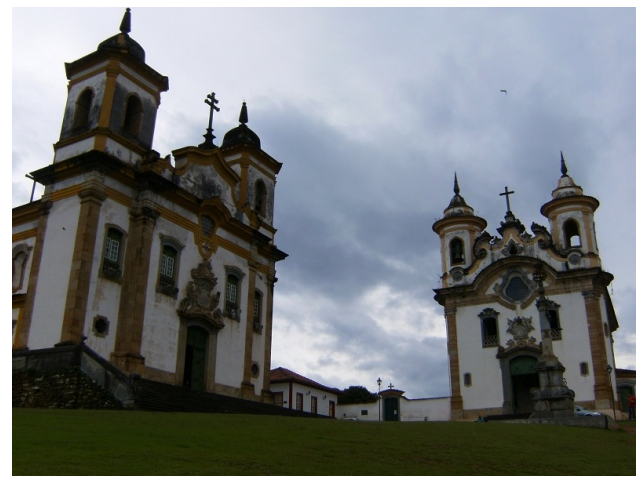

Fig. 4 - Espacialidade barroca, em Mariana, Minas Gerais, Brasil (Maio 2013).

Figura a cores disponível online.

Fig. 4 - Baroque spatiality, in Mariana - Minas Gerais, Brazil (May 2013).

Colour figure available online.

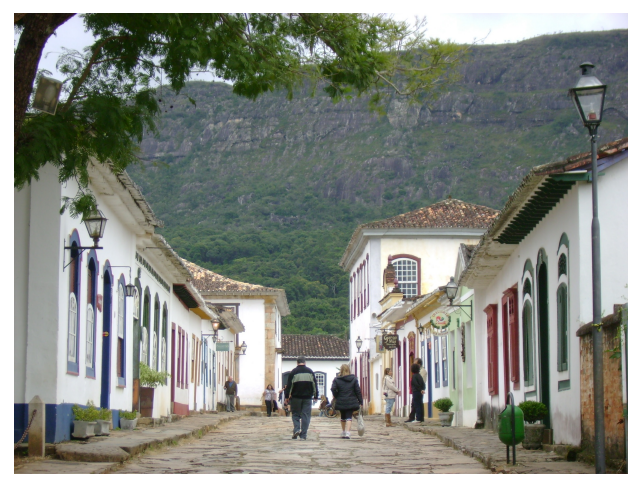

Fig. 5 - Rua Direita, em Tiradentes, Minas

Gerais, Brasil (Fevereiro 2012).

Figura a cores disponível online.

Fig. 5 - Street Right, in Tiradentes - Minas Gerais, Brazil (February 2012).

Colour figure available online.

A paisagem barroca como memória estética nacional advém do movimento histórico que não se inicia nem se encerra no Brasil. Castedo (1993) diz que o barroco serviu para que a independência cultural do Brasil emergisse antes da independência política; inaugura-se uma mestiçagem (espanhol com o indígena e português com o africano) e o consequente enraizamento das formas e do espírito do barroco, respectivamente, nos aglomerados e no próprio povo.

Simmel (2011, p. 42) é categórico ao afirmar que "raramente se esclareceu que ainda não há paisagem pelo facto de coisas de toda a sorte se estenderem umas ao lado das outras sobre uma parcela de território e serem imediatamente olhadas". Nesse aspecto, justifica-se a paisagem barroca como memória estética nacional ao considerar, para além do produzido no território, os elementos subjetivos deste material que constitui a memória. A paisagem que caracteriza, individualmente, algumas das cidades de origem colonial portuguesa, no Brasil, não é entendida como unidade autossuficiente. Ao contrário, essa paisagem barroca faz-se memória estética nacional por ser elemento de conexões permanentes, parte de uma totalidade que se reproduz em consonância com a totalidade histórica do Absolutismo, do Mercantilismo, do Bulionismo e da nobilitação do urbano, em resumo, essa paisagem barroca memória estética nacional parte da empresa colonizadora desde a Península Ibérica e atinge o fazer de uma arte turística internacional, na atualidade. Deve-se questionar, todavia, se a paisagem e o território despontam como referências de identidade coletiva e/ou capital simbólico; fundamento material e subjetivo da homogeneidade-heterogeneidade cultural e econômica nacionais, em cada cidade que guarda a arte barroca. "O território, na formação estatal-nacional, deve ser conceituado como produtor nominativo e constitutivo da identidade e presença referencial" (Escolar, 1996, p. 109). 
Nesse contexto, os objetos estéticos da colonização portuguesa na América (materializados nas cidades coloniais), desde sua apresentação, são cultuados sem a carga de dominação que carregaram desde a sua gestação, os quais compõem tal memória estética. O jugo colonial permanece na paisagem, na matéria, no espírito, na dinâmica das cidades e da arte, mas, merece ser decifrado em nome das minorias étnicas negligenciadas; a busca de uma memória estética por meio da paisagem serve-se, também, a tal deciframento. A arte e o urbanismo barrocos podem ser lidos como objetos híbridos da busca pelo controle territorial, e não como meras caricaturas da história do território; a produção de uma identidade nacional baseada na retomada de um passado caricaturizado possibilita apagar memórias contraditórias e ocultar a concretude da expansão ultramarina (Costa \& Suzuki, 2012). A memória estética nacional impressa na paisagem barroca de cidades brasileiras é a memória das contradições que permearam o processo colonizador e de uma colonialidade perene ${ }^{\mathrm{vi}}$.

A memória estética nacional, então, apresenta dois elementos caracterizadores adjacentes, complementares, reciprocamente formadores, contidos na paisagem barroca: o formal e o espiritual. Pode-se dizer, por um lado, que há notável uniformidade entre as igrejas da costa brasileira e os modelos portugueses; arcos, portadas, partes significativas de templos foram importadas da Europa para o Nordeste, ou que o barroco da zona mineradora ganhou feição própria em terras brasileiras pela geohistória da Colônia, face à economia mundo (Braudel, 1985) em constituição; por outro lado, é necessário reconhecer que essa produção material incorpora o espírito de um sistema de dominação colonial que promove uma dinâmica contraditória: arte religiosa e organização social que amparavam um sistema rudimentar de controle e de exploração próximo ao feudal. $\mathrm{O}$ espírito barroco, no Brasil, traz a diversidade de culturas autóctones, no interior e no litoral, o que requer a reinterpretação da arte em seus próprios termos - eram mensagens chegadas do Ocidente e decodificadas aos próprios gostos e gestos locais. A paisagem barroca enquanto memória estética nacional é signo de uma sociedade colonial estabelecida sobre antigas civilizações conquistadas, com uma estratificação social e cultural baseada na lógica do mundo metropolitano de origem (ocorrência por toda América Latina), mas que se fez em processos longos de hibridização.

A paisagem barroca como elemento de memória estética nacional guarda não apenas um estilo artístico, mas uma expressão civilizacional representada, teatralmente, nas cidades, nos cultos da religião, na música e na pintura. "No relato dos festejos que, em 1733, assinalaram a inauguração da nova igreja Matriz de N. Sra. do Pilar (...) o Triunfo Eucarístico, ao descrever com minúcia o fausto das igrejas, os trajes e alegorias, as danças e músicas, os cenários, a ornamentação e a pompa litúrgica, salienta que Villa Rica, mais que esfera da opulência, he teatro da Religião (Goulão, 1993, p. 65). Essa passagem da histórica festividade sacra do Triunfo Eucarístico, na antiga Vila Rica, em Minas Gerais, reforça o espírito barroco do controle ecumênico; retrata uma ordem ampla que se irradia da crença disseminada e ilimitada no divino absoluto. A figura 6 retrata atual culto barroco (cânticos em latim, exuberância do incenso, enaltecimento do divino e a contraposição do céu e do inferno), na Igreja Matriz de Nossa Senhora do Pilar, em São João del-Rei, Minas Gerais. 


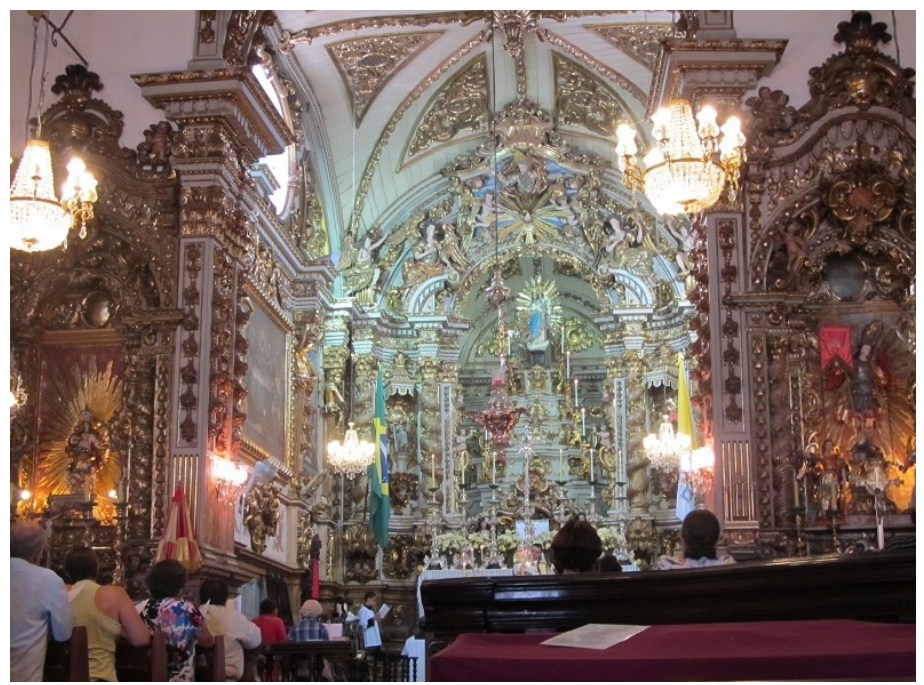

Fig. 6 - Culto na Igreja Matriz do Pilar, em São João del-Rei, Minas Gerais, Brasil (Janeiro 2013).

Figura a cores disponível online.

Fig. 6 - Worship the Church of the Pillar, in São João del-Rei, Minas Gerais, Brazil (January 2013). Colour figure available online.

Exemplo notório da arte barroca religiosa que assinala, inclusive, um trânsito pelo território, a indicar uma paisagem barroca singular e replicada, são as capelas-mores das igrejas matrizes de São João del-Rei (MG) [figura 6], Ouro Preto (MG) e Catas Altas (MG). O trânsito entre artistas, arte e interesses metropolitanos leva a tal conjunção.

"De datas e nomes conhecidos, de coluna berminiana e composição ornamental simétrica. E a da matriz de São João del-Rei, também de coluna berminiana, já apresentando maneira de conceber e certos termos de vocabulário libertos das proposições da época, recebeu naturalmente a posteridade de uns poucos anos, por todos aceita. Foi também o que levou a se estabelecer Francisco Xavier de Brito como o introdutor na região da linguagem joanina na sua expressão maior. Raciocínio que perdurou até hoje, consolidado pelo tempo." (Martins Costa, 1997, p. 423-424).

Esta análise de similitude feita diz respeito a traços da arte religiosa barroca, na zona mineradora brasileira. Contudo, pode-se dar exemplos, também, de traços urbanísticos que se sobrepõem, de maneira a não desconsiderar que são os próprios objetos como as casas de câmaras e cadeias, pelourinhos, palácios, igrejas, sobrados, pontes de pedras, traçados das ruas, desenhos das praças e largos, que constituem e dão forma aos conjuntos, caracterizam a cidade colonial no Brasil, não seguindo à risca o ritmo em arquitetura. Coelho Netto (2007, p. 133) menciona que o ritmo tem a finalidade de pôr em prática três princípios muito caros ao pensamento renascentista: princípio de equilíbrio, princípio da continuidade e princípio da passagem do todo para as partes. Cita P. A. Michelis para completar o conceito; "o ritmo permite-nos adivinhar que vai seguir-se um golpe rítmico ou uma certa série de golpes, assim como mais ou menos o efeito segue a causa. Antes 
portanto que o golpe se produza nós já o esperamos, e quando ele acontece segue-se em nós uma sensação muito rápida de satisfação." A partir dessa ideia do ritmo em arquitetura, é possível dizer que a cidade colonial brasileira setecentista não o respeita, foge da arte e arquitetura renascentistas e adota uma nova concepção de organização espacial significante do barroco. ${ }^{\mathrm{vii}}$

O tortuoso é um dos elementos fundamentais para a animação de um espaço, para sua dinâmica, para a eliminação do tédio do habitar, para o aniquilamento da retidão de avenidas e suas paralelas perpendiculares (Coelho Netto, 2007). É a própria tortuosidade e as estratégias construtivas imperantes nas cidades coloniais brasileiras (especialmente na zona mineradora) que dão a impressão de haver sempre algo a conhecer, a descobrir, a viver. É essa irregularidade a melhor expressão urbana possível, dadas as possibilidades locais e de época - faz-se o diferencial que dá sentido às feições de urbanismo barroco característico na zona mineradora; é essa irregularidade, a tortuosidade, a complicação do sentir e da expressão próprias do barroco que caracterizam esse urbanismo português para uma estratégia espacial colonial. viii

Muitos são os exemplos de semelhanças artísticas ou urbanísticas oriundas dos trânsitos da arte, de artistas e engenheiros militares pelo território da antiga Colônia. Contudo, o intuito não é fazer uma historiografia da arte ou do urbanismo barrocos, mas deixar pistas metodológicas geográficas de um olhar diferenciado para a paisagem das cidades barrocas no Brasil e na América Latina, com um viés na arte que aproxima configuração territorial e produção da paisagem. A arte barroca, da pintura às representações sacras imagéticas e ao urbanismo característico dessas cidades coloniais, fez-se elemento de amálgama entre Estado, Igreja e Sociedade Civil, consolidando o Estado Absoluto. A liberdade relativa de artistas favoreceu os deslocamentos na arte, da arte, da arquitetura e da paisagem urbana, os quais expressam a busca de um refúgio do jugo colonial, que se fez com traços semelhantes em diferentes pontos do território.

Controle e liberdade são palavras de ordem das diferentes expressões memoriais da Colônia, uma delas, a arte e o urbanismo barrocos. Um território extenso e diferenciado geograficamente, uma população híbrida e em constituição, relações de classe bem pontuadas, o Estado e a Igreja como agentes do processo de produção do espaço colonial e a arte a aglutinar todo esse movimento (fazendo-se singular em singulares regiões), sincretizam a expressão máxima da paisagem barroca como elemento de uma memória estética nacional. As figuras 7 e 8 trazem elementos comuns da arquitetura colonial, desde a tipologia dos edifícios à sua funcionalidade histórica residencial e/ou comercial. Como síntese da história passada do território, fazem-se elementos paisagísticos da memória estética nacional, hoje. 


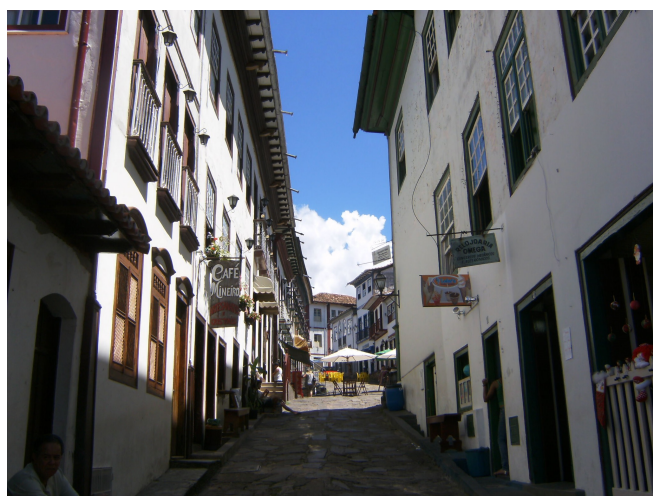

Fig. 7 - Beco da Tecla, em Diamantina, Minas Gerais, Brasil (Dezembro 2011). Figura a cores disponível online.

Fig. 7 - Pass key, in Diamantina - Minas Gerais, Brazil (December 2011).

Colour figure available online.

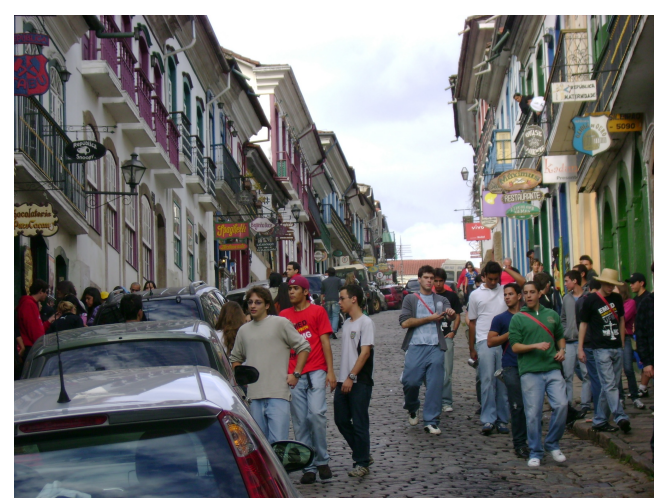

Fig. 8 - Rua Direita, em Ouro Preto, Minas Gerais, Brasil (Dezembro 2011). Figura a cores disponível online.

Fig. 8 - Street Right, in Ouro Preto - Minas Gerais, Brazil (December 2011). Colour figure available online.

A arte religiosa e os traços de um urbanismo barroco localizam-se em algumas porções centrais e litorâneas do território brasileiro, como expressões presentes da saga econômica europeia moderna, a qual carregou consigo a expectativa da conquista e do enriquecimento rápido. Em seu trânsito, imprimiu uma lógica de fazer cidades própria a Portugal e a Espanha. Estas cidades americanas ganharam feição singular ou própria, ante as condições geográficas e as possibilidades da nova terra e do processo urbano embrionário, que ocorria pari passu à colonização. A matéria e o espírito barrocos embrenharam-se em terras conquistadas e se mantiveram; o antigo controle social pelo barroco transmutou-se no atual frenesi social pelo barroco, que consagra uma arte turística.

Memória estética e território forjado assinalam, no Brasil, a aura de um Estado-nacional que só pode ser compreendido na hibridez dos povos que o constituem: o indígena, o negro, o asiático e o europeu que, juntos e em desiguais escalas de poder e representatividade social, deram corpo à paisagem barroca da memória estética nacional. Dentro da ideia de nação e nacionalidade assumidas na introdução deste trabalho, pode-se dizer que faltou e parece faltar ao Brasil elaborar representações de formas materiais e simbólicas mais inclusivas (mesmo no contexto do barroco), para poder fundar - ideologicamente - nacionalidades locais, com o resgate dos sentimentos patrióticos preexistentes e à sua articulação em um molde histórico comum que priorize o país em sua complexidade e em respeito à construção e à transmissão social eficiente de visões territoriais e artísticas que escapem de legitimidades nacionais conservadoras e discricionárias. 


\section{CONSIDERAÇÕES FINAIS}

Por meio da paisagem, o geógrafo pode desvendar partes consideráveis do movimento histórico do mundo, buscar os sentidos contraditórios (ou não) do território. As paisagens refletem as relações sociais e possibilitam reconhecer o papel da arte, dos objetos e das técnicas agregadas ao território. No limite, a histórica ressignificação do barroco, no Brasil, leva ao ordenamento total do território urbano, nas cidades-patrimônio do presente.

Eric Dardel, em O Homem e a Terra, afirma que a paisagem é muito mais que a justaposição de detalhes pitorescos, é um conjunto, uma convergência, um momento vivido, uma ligação interna, uma impressão, que une muitos elementos. A análise apresentada sobre a paisagem barroca brasileira traça-a como particularidade catalisada pela totalidade histórica europeia, ou seja, essa paisagem é elemento singular que resulta das realizações espaciais que atravessam a modernidade afirmada e negada pela colônia portuguesa na América. A paisagem barroca é categorizada como desdobramento geohistórico global e elemento de memória estética nacional, a qual ganha feições próprias em território brasileiro e mesmo na América Latina.

Vê-se a interpretação da paisagem barroca brasileira como mais uma possibilidade de compreensão da história do território; faz-se horizonte de análise onde o movimento da arte sugere o território entre escalas variadas da existência e manutenção da geopolítica colonial. Ao campo do saber geográfico não cumpre se ocupar da arte pela arte; à Geografia resta ratificar (em estudos que trazem discussão sobre o lugar da arte) seu viés analítico-metodológico central, que é a do desvendamento das estratégias e contradições produtoras de distintas espacialidades e particulares paisagens. Por isso, defende-se que a leitura da paisagem barroca (como elemento de memória estética nacional) perpassa a relação dialética entre universalidade-particularidade-singularidade na forja do território. Por intermédio da paisagem barroca, salta-se da arte como elemento estético puro para se atingir a memória como estética nacional vinculada à história do território forjado. Porém, cabe relembrar que a paisagem barroca devém das diferentes intencionalidades sociais estabelecidas nos cinco mais notórios eventos históricos de sua ressiginificação, no Brasil: da Gênese colonial do patrimônio até a sua produção simbólica, projeção inicial, banalização pela cenarização progressiva e, por fim, do questionamento das possibilidades efetivas de seu empoderamento popular, no país. A indicação da paisagem barroca como memória estética nacional deseja sintetizar, teoricamente, estes cinco momentos já discutidos em trabalho anterior (Costa, 2011), sugerindo a força de seu devir.

A questão da temporalidade abordada neste trabalho (do período colonial ou genético do barroco à sua projeção global contemporânea) é reveladora de diferentes apropriações da paisagem (de sua potência estética para o controle sacro-estatal-social colonial à sua virtude simbólica ou fator da econômica urbana atual), o que conduz à ideia de nacionalidade que o próprio barroco passa a representar, em estratégia arbitrária do Estado e do mercado. Entretanto, cabe frisar que a paisagem barroca que se desejou e que 
se deseja como memória estética nacional pouco contribuiu para compreender, em essência, as contradições do processo colonizador. Para muito além de um conceito de época, cujo epicentro foi a Europa - como indicado por Maravall (2009) -, trata-se o barroco como fato histórico, com arte de base territorial, contributo de nacionalidade e de exclusiva economia urbana, na América Latina e, especialmente, no Brasil, ontem e hoje, em seu devir. A paisagem barroca latino-americana, assim, fez-se e faz-se artifício ou arma política territorializada (arte passível de ressignificação histórica).

Este olhar geográfico para a paisagem barroca brasileira ainda requer maior aprofundamento, em diálogo com essa paisagem na América Latina. $\mathrm{O}$ trabalho aqui introduzido quer se fazer, minimamente, estímulo a novas incursões nessa temática, que envolve a geografia das cidades coloniais do Brasil (pouco retratada neste campo do saber). A leitura do barroco para além de objeto de culto artístico (mas, como uma filosofia totalizadora da história moderna europeia transplantada ao Brasil, com base espacial), tem fundamento potencial na Geografia, ao se considerar totalidades escalares reprodutoras dessa arte, conexões políticas que a ressignificam, extensões econômicas que fazem da mesma estratégia de controle e distâncias existenciais que favorecem sua função de persuasão, tudo embutido em conteúdo na paisagem produzida e no território ordenado, historicamente.

\section{REFERÊNCIAS BIBLIOGRÁFICAS}

Bayón, D. (1982). Reflexiones para la comprensión del fenómeno barroco. Revista Barroco, n(12), 32-38.

Bosi, A. (1986). Cultura como tradição. In G. Bornheim (Ed.), Tradição Contradição (pp. 121-139). Rio de Janeiro: Jorge Zahar Editor.

Braudel, F. (1985). La dynamique du capitalisme. Paris: Les Editions Arthaud.

Brenna, G. R. (1982). Medieval ou Barroco? Proposta de leitura do espaço urbano colonial. Revista Barroco, $n(12), 141-146$.

Castedo, L. (1993). El barroco y su decoración - de Roma al mestizaje americano y a la identidad brasileña. Revista Barroco, $n(17)$, 261-272.

Coelho Netto, J. (2007). A construção do sentido na arquitetura. São Paulo: Editora Perspectiva.

Costa, E. B., \& Suzuki, J. C. (2012). A ideologia espacial constitutiva do Estado nacional brasileiro. Scripta Nova. Revista Electrónica de Geografía y Ciencias Sociales, V(XVI), (418), 01-14.

Costa, E. B. (2011). Totalidade urbana e totalidade-mundo - as cidades coloniais barrocas face à patrimonialização global. (Tese de Doutorado). Disponível em: http://www.teses.usp.br/teses/disponiveis/8/ 8136/tde-14032011-104656/pt-br.php
Costa, E. B. (2009). A dialética da construção destrutiva na consagração do Patrimônio Mundial: o caso de Diamantina. (Dissertação de Mestrado). Disponível em: http://www.teses.usp.br/teses/ disponiveis/8/8136/tde-05022009-150209/ pt-br.php

D’Angelo P. (2011). Os limites das actuais teorias da paisagem - e a paisagem como identidade estética dos lugares. In A. Serrão (Ed.), Filosofia da paisagem - uma antologia (pp. 419-439). Lisboa: Centro de Filosofia Universitária.

Dardel, E. (2011). O homem e a terra: natureza da realidade geográfica. Trad. Werther Holzer. São Paulo: Editora Perspectiva.

Goulão, M. (1993). Os estudos de história da arte portuguesa na América Latina. Revista Barroco, $n(17)$, 61-67.

Escolar, M. (1996). Crítica do discurso geográfico. São Paulo: Hucitec.

Hauser, A. (1969). Historia social de la literatura y el arte - maneirismo, barroco, rococó, classicismo e romantismo. Madrid: Ediciones Guadarrame.

Holanda, S. B. (1995). Raízes do Brasil. São Paulo: Cia das Letras. 
Machado, L. G. (1973). Barroco Mineiro. São Paulo: Editora Perspectiva.

Maravall, J. (2009). A cultura do barroco. São Paulo: Editora da USP.

Martins Costa, L. (1997). Importância da capela-mor da matriz de São João del-Rei. In A. Ávila (Ed.), Barroco Teoria e Análise (pp. 423-441). São Paulo: Editora Perspectiva.

Mumford, L. (1991). A cidade na história: suas origens, transformações e perspectivas. São Paulo: Editora Martins Fontes.

Neves, J. (1986). Ideias filosóficas no barroco mineiro. São Paulo: Editora da USP.

Ritter, J. (2011). Paisagem. Sobre a função do estético na sociedade moderna. In A. Serrão (Ed.), Filosofia da paisagem - uma antologia (pp. 489-507). Lisboa: Centro de Filosofia Universitária.

Romero, J. (2009). La ciudad occidental - culturas urbanas en Europa y América. Buenos Aires: Siglo XXI Editores.

Santos, M. (2002). A natureza do espaço: técnica, tempo, razão e emoção. São Paulo: Editora da USP.

Simmel, G. (2011). Filosofia da paisagem. In A. Serrão (Ed.), Filosofia da paisagem - uma antologia (pp. 39-58). Lisboa: Centro de Filosofia Universitária.

Smith, R. (1969). Arquitetura civil do período colonial. Revista do Patrimônio Histórico e Artístico Nacional, $n(17)$, s. n. t.

i Fundamentado no suíço Reinrich Wolfflin, Neves (1986) reinterpreta o barroco ao final do século XIX, reconhece que a obra ou fenômeno representa: 1) passagem do linear clássico para o pictórico barroco (objetos não se encontram mais isolados entre si); 2) passagem da utilização de planos, no clássico, para a noção de profundidade no barroco; 3) passagem da forma fechada clássica à forma aberta barroca (ideia de permanente caminhar, movimento, instabilidade); 4) passagem da pluralidade clássica à unidade barroca (vida de cada uma das partes se subordina ao conjunto); 5) passagem da luz absoluta do clássico à luz relativa do barroco (dramatização do claro-escuro).

ii O Concílio de Trento realizou-se de 1545 a 1563, para assegurar a unidade da fé (Contra-Reforma) e a disciplina eclesiástica (uma reação à divisão religiosa então vivida na Europa).

iii Para melhor elucidação desta temática, ver a tese de doutoramento do autor intitulada Totalidade urbana e totalidade-mundo: as cidades coloniais barrocas face à patrimonialização global, a qual indica uma periodização para a compreensão da consagração do patrimônio cultural no Brasil, bem como trata do lugar desses bens na constituição do Estado nacional brasileiro.

iv Para relembrar, de acordo com Santos (2002), um evento é, simultaneamente, a matriz do tempo e do espaço; um evento não se repete, são, pois, todos novos. Na verdade, os eventos mudam as coisas, transformam os objetos, dando-lhes, ali mesmo onde estão, novas características.

v Serviço do Patrimônio Histórico e Artístico Nacional.

vi Para o debate da colonialidade, ver pós-colonialistas, notoriamente latino-americanos.

vii Essa discussão do ritmo em arquitetura foi apresentada, originalmente, em Costa (2009), em diálogo com Coelho Netto (2007); o debate foi retomado pela demanda do tema deste artigo.

viii Debate retomado de Costa (2009). 